\title{
Flawed estimates of cognitive ability in Clark et al. Psychological Science, 2020
}

\author{
Christian L. Ebbesen ${ }^{1,2, \bigotimes}$ \\ ${ }^{1}$ NYU Neuroscience Institute, New York University, New York, NY 10016, USA. \\ ${ }^{2}$ Skirball Institute of Biomolecular Medicine, NYU School of Medicine, New York, NY 10016, USA.
}

\begin{abstract}
In a recent paper, Clark et al. (2020) analyze the relationship between socio-economic measures and estimates of average cognitive ability ('IQ') in 140 countries. According to the data presented by the authors, several African, South Asian and Central American countries have an average IQ below 50 (i.e. intellectually disabled, according to DSM diagnostic criteria). Moreover, according to the data presented by the authors, the average cognitive ability of adults in African nations is $\sim 1.6$ standard deviations below the cognitive ability of European adults. These notions are incompatible with psychological science and all conclusions drawn from these data are invalid.
\end{abstract}

Correspondence: C.L.E. (christian.ebbesen@nyumc.org)

\section{Introduction}

IQ scores ${ }^{1}$ are a poor measure of cognitive ability, prone to cultural biases in testing paradigms and highly sensitive to systematic biases in population sampling (Gould, 1981; Richardson, 2002; Hampshire et al., 2012). Biased and incorrect estimates of average IQ in non-European populations historically was - and still is - a core component of scientific racism within psychology (Belkhir, 1994). In a recent paper, Clark et al. (2020) investigate the relationship between IQ scores as an estimates of average cognitive ability and other socio-economic statistics in 140 countries (Fig. 1a). The authors present estimates of 'national IQ'. The definition of 'national IQ' is not given in Clark et al. (2020), but can be found in Lynn and Meisenberg (2010): 'national IQ' is defined such that the 'national IQ' of the United Kingdom is 100, and the standard deviation of IQ scores within the United Kingdom is 15. In other words, 'national IQ' is claimed to be standardized such that these scores allow direct comparison of cognitive ability between populations. Thus, if a country has a 'national IQ' of 115, it means that - on average - an individual from that country would receive an IQ score of 115 in the United Kingdom.

Within a comparable population, as a rough indicator, extremely low IQ scores can be a sign of clinically significant cognitive impairments, such as intellectual disability (Boat and $\mathrm{Wu}, 2015)$. In DSM-IV (APA, 1998), intellectual disability was partly diagnosed by an IQ score of below 70 (i.e.

\footnotetext{
${ }^{1} \mathrm{An}$ IQ score is a measure of performance on a cognitive test, defined in relation to the performance of other individuals on the same test. Mathematically, the IQ score is a re-scaled $z$-score, scaled such that an individual with a performance equal to the population mean receives an IQ score of 100. IQ scores are usually normalized such that the standard deviation is 15 (individuals performing one standard deviation above average are assigned a score of 115).
}

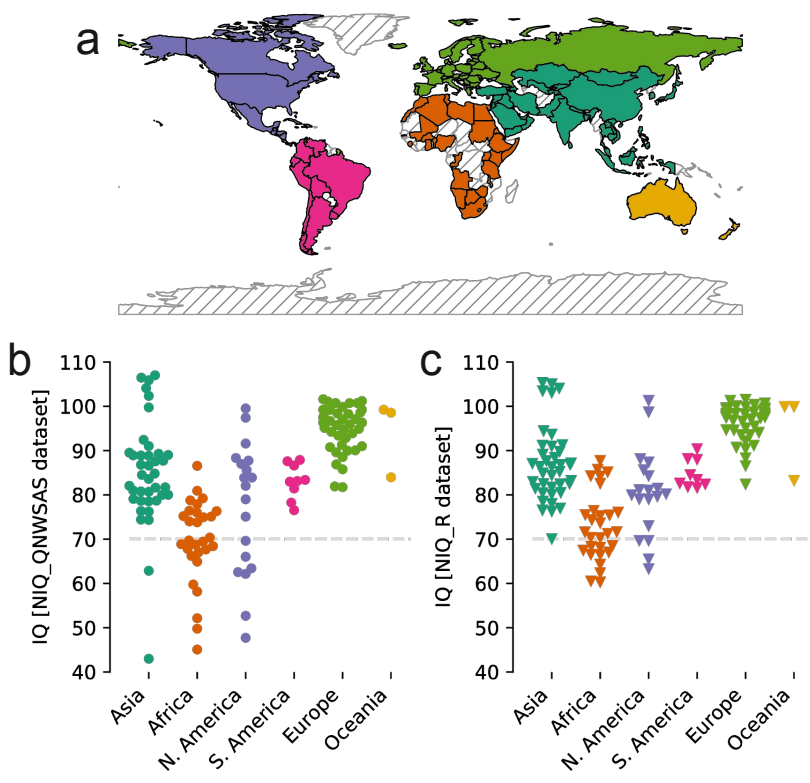

Fig. 1. Estimates of cognitive ability in the Clark et al. (2020) data. a, Countries included in the Clark et al. (2020) analysis of 'national IQ'. b-c, Distribution of national IQ estimates across continents in the 'NIQ_QNWSAS' and 'NIQ_R' datasets. Dot/triangles indicate the average national IQ of one country, dotted vertical line indicates the DSM-IV criterion for intellectual disability.

\begin{tabular}{|c|c|c|c|}
\hline Severity & Cases & DSM-IV & DSM-5 \\
\hline Mild & $1.96 \%$ & IQ: $50-69$ & $\begin{array}{l}\text { Can live independently with minimum } \\
\text { levels of support. }\end{array}$ \\
\hline Moderate & $0.23 \%$ & IQ: $36-49$ & $\begin{array}{l}\text { Independent living may be achieved } \\
\text { with moderate levels of support, such } \\
\text { as those available in group homes. }\end{array}$ \\
\hline Severe & $0.08 \%$ & IQ: $20-35$ & $\begin{array}{l}\text { Requires daily assistance with self- } \\
\text { care activities and safety supervision. }\end{array}$ \\
\hline Profound & $0.03 \%$ & $\mathrm{IQ}<20$ & Requires 24-hour care. \\
\hline
\end{tabular}

Table 1. Diagnostic criteria for intellectual disability in DSM-IV and DSM-5 'Cases' indicates approximate incidence of mild, moderate, severe, and profound intellectual disability in the population. Table adapted from Boat and Wu (2015).

two standard deviations below the mean of 100 in the population). In recognition of the methodological issues with IQ scores as a measure of cognitive ability in general, in DSM-5 (APA, 2013), the use of IQ scores were replaced by descriptions of the level of support needed by an individual to function (Table 1). Individuals with intellectual disabilities are rare in the population, with $\sim 1.96 \%$ displaying mild symptoms (IQ: 50-69) and $\sim 0.35 \%$ displaying moderate, severe or profound symptoms (IQ $<50$, unable to live independently without moderate levels of support).

\section{Issues with the Clark et al. (2020) data}

Clark et al. (2020) present three datasets of 'na- 
tional IQ' ('NIQ'): 'NIQ_LV12GeoIQ', 'NIQ_R' and 'NIQ_QNWSAS'. The dataset 'NIQ_LV12GeoIQ' is described as being based on data sourced from Lynn and Vanhanen (2012). The dataset 'NIQ_R' is sourced from Becker and Rindermann (2016), which bases the estimates on Lynn and Vanhanen (2012). The estimates in 'NIQ_LV12GeoIQ' and 'NIQ_R' are almost identical. The dataset 'NIQ_QNWSAS' is from an online repository (Becker, 2019) associated with Lynn and Becker (2019), described by Clark et al. (2020) as being based on Lynn and Vanhanen (2012) combined with "data from school assessment studies-mainly Progress in International Reading Literary Study (PIRLS), Programme for International Student Assessment (PISA), and Trends in International Mathematics and Science Study (TIMSS)".

We extracted the estimates of national IQ from the Clark et al. (2020) online supplementary data and discovered serious flaws. In both the 'NIQ_QNWSAS' dataset (Fig. 1b) and the 'NIQ_LV12GeoIQ'/'NIQ_R' datasets (Fig. 1c), several countries were assigned an average national IQ scores well below 70, the DSM-IV diagnostic criterion for intellectual disability. For example, in the 'NIQ_QNWSAS' dataset, several African, South Asian and Central American countries have an average IQ below 50, such as Nepal (national IQ: 43.0), Sierra Leone (national IQ: 45.1), Guatemala (national IQ: 47.7) and Gambia (national IQ: 49.8). These estimates would seem to suggest that a majority of the population in these countries are moderately, severely or profoundly cognitively impaired (cf. Table 1). This notion is incompatible with psychological science and there is no doubt that these estimates are wrong.

Comparing the data across continents, we observed a strong systematic bias in the estimates of cognitive ability. According to the estimates analyzed by Clark et al. (2020), the national IQ of African countries (Fig. 2a) is 24.4 points lower than the national IQ of European countries (mean IQ: $69.6 \mathrm{v}$. 94.9 for the 'NIQ_QNWSAS' dataset, $72.3 \mathrm{v}$. 96.2 for the 'NIQ_R' dataset, both $\mathrm{p}<0.001, \mathrm{~N}=29 / 41$, Mann-Whitney U-test, Fig. 1b-c). This is a huge mean difference ( $\sim 1.6$ standard deviations), similar in magnitude to the the DSM-IV diagnostic criterion for intellectual disability (2 standard deviation). There is no doubt that these estimates of national IQ for African nations are incorrect.

In addition to the impossibly low estimates of national IQ, we also note that there are large, unexplained disagreements between the 'NIQ_QNWSAS' dataset and the 'NIQ_LV12GeoIQ'/'NIQ_R' datasets, for example for Nicaragua $(\Delta \mathrm{IQ}=28.7)$, Djibouti $(\Delta \mathrm{IQ}=19.4)$, Haiti $(\Delta \mathrm{IQ}$ $=20.7)$, Sierra Leone $(\Delta \mathrm{IQ}=17.2)$, Guatemala $(\Delta \mathrm{IQ}=32.2)$ and Honduras $(\Delta \mathrm{IQ}=18.0)$ (Fig. 2a). These large discrepancies are a reflection of the fact that the methods used to estimate national IQ are flawed and unreliable.

\section{Why are these IQ estimates so wrong?}

All estimates presented by Clark et al. (2020) are based on estimates in Lynn and Vanhanen (2012), which is a revised and extended version of estimates first presented in Lynn and Vanhanen (2002). Several authors have cataloged grave methodological issues with previous iterations of the national IQ datasets by Lynn and colleagues, including the use of nonrepresentative samples, biased inclusion and exclusion of data, and miscalculations (Richardson, 2004; Wicherts et al., 2010c,a,d; Loehlin, 2007; Dickins et al., 2007).

Evidently, the data quality issues persist in the most recent iteration of the national IQ estimates (the 'NIQ_QNWSAS' dataset, Becker, 2019). A full review of the methodological issues is beyond the scope of this note, but to give a sense of the issues with data quality, we list a few examples. The estimate for Somalia (national IQ: 67.7) is based on a single sample of Somali refugees aged 8-18 tested in the Daadab refugee camp in Kenya (Bakhiet et al., 2017). The estimate for Haiti (national IQ: 83.9) is based on a sample of 133 rural 6-yearolds (de Ronceray and Petit-Frere, 1975) and a sample of 54 individuals with a mean age of 10 years (Cotten, 1985). The estimate for Botswana (national IQ: 69.5) is based on a single sample of 104 ethnically Tswana high-school students aged 17-20 (natively Tswana-speaking), tested in English in South Africa (Maqsud, 1997). The estimate for Burkina Faso (national IQ: 73.8) is based on a single sample of rural children aged 5-15 (Bagby, 2011). The estimate for Nepal (national IQ: 43.0) is based on samples of rural vitamin-A-deficient children (Buckley et al., 2013), rural mothers in experimental nutrient supplement trials (Christian et al., 2010) and rural rice paddy and wheat farmers surveyed in the agricultural year 1977-1978 (Jamison and Moock, 1984). The estimate for Nabimia (national IQ: 66.2) is based on a single sample of 103 Herero-speaking children aged 7-12 (Veii, 2003). The estimate for Saint Vincent and the Grenadines (national IQ: 63.4) is based on a single sample of 174 rural children aged 8-11 (Durbrow et al., 2002). The estimate for Malawi (national IQ: 69.7) is based on a sample of children aged 7-14 (7.5\% never having attended school, $14.6 \%$ school dropouts) from villages in a rural district where $76.1 \%$ of the population lives below the World Bank's international poverty line (Van de Vijver and Brouwers, 2009).

From these examples, it is clear that the problem of 'national IQ' as a metric of cognitive ability is not just that IQ tests are inherently culturally biased, or that the mathematical strategy used to standardize raw IQ scores from one country to a common 'national IQ'-standard is unreliable. Rather, the underlying raw data is so extremely unrepresentative that it is impossible to correct these data for biased sampling.

\section{Discussion}

The notion that the average IQ of whole countries is below 50 (intellectually disabled, unable to live independently without moderate levels of support, according to DSM-IV diagnostic criteria) is evidently wrong. It is also impossible that the average IQ of African nations is $\sim 1.6$ standard deviations below the average IQ of European nations. As pointed out by Wicherts et al. (2010b), presenting such low IQ estimates is equivalent to claiming that African adults have the cognitive ability of an average 11-year-old European child. This notion is incompatible with psychological science. 


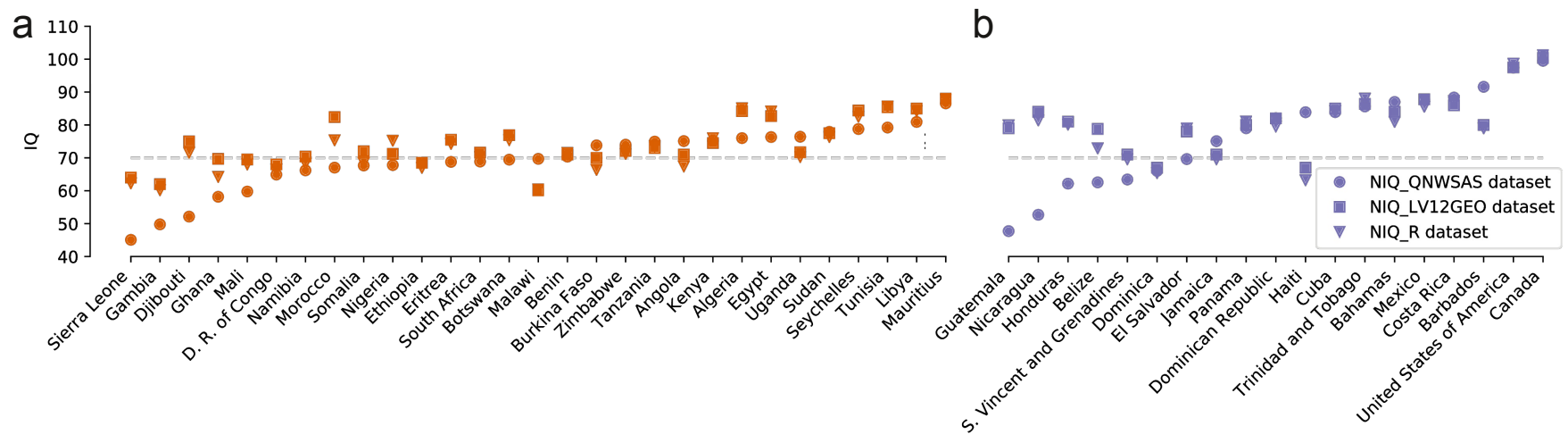

Fig. 2. Average IQ of African and North American countries in the Clark et al. (2020) data. Dots/squares/triangles indicate IQ estimates in the 'NIQ_QNWSAS', 'NIQ_LV12GeolQ' and'NIQ_R' datasets. Dotted vertical line indicates the DSM-IV criterion for intellectual disability.

About the quality of the IQ estimates, Clark et al. (2020) write that

To our knowledge, these are the most complete and well-validated country-level IQ data available (Lynn \& Meisenberg, 2010), but the quality of the data varies by country. [...] Note also that noise in the data, if anything, should obscure our hypothesized pattern of results.

This is incorrect. As outlined in the previous section, for many countries outside Europe, the Clark et al. (2020) IQ estimates are based on samples of poorly educated individuals (including children and refugees), often living below the poverty line. Extrapolating 'national IQ' estimates from biased and unrepresentative samples results in biased and inaccurate data. The errors in the Clark et al. (2020) data do not constitute random noise, which might simply mask true statistical interactions. These data are so biased that any conclusions drawn from them are invalid.

There is no scientific justification for the discussion by Clark et al. (2020) of "societies with relatively high average intelligence", "societies with relatively low average intelligence.", "populations with relatively lower mean cognitive ability" or "more cognitively advantaged populations".

In the case of Clark et al. (2020), pre-publication peer review failed to detect that serious flaws in their underlying data render their conclusions invalid. As a practical suggestion to help avoid such failures in the future, we suggest that the editors of Psychological Science mandate that authors not just provide summary statistics in tables, but also include plots showing the underlying raw data points. The gross flaws in the data reported by Clark et al. (2020) (impossibly low IQ estimates) would have been immediately obvious to any referee presented with such a plot. Plotting raw data points is standard practice in many experimental fields and major journals (e.g. Nature Neuroscience) do not accept manuscripts with only summary statistics.

\section{Conclusion}

The estimates of cognitive ability presented by Clark et al. (2020) are so flawed that it is impossible to draw any conclusions from their analysis. The paper should be retracted.

\section{ACKNOWLEDGEMENTS}

We thank Ella Podvalny and Thomas Baumgarten for comments on the manuscript. We were made aware of the Clark et al. (2020) paper via a tweet by Olajide Bamishigbin. Further examples of methodological issues with the national IQ estimates in the 'NIQ_QNWSAS' dataset have been pointed out on twitter by Rebecca Sear. C.L.E. is supported by a postdoctoral fellowship from the Novo Nordisk Foundation. This paper was typeset using a slightly modified version of the bioR $\chi$ iv preprint template created by the Henriques Lab at UCL.

\section{AUTHOR CONTRIBUTIONS}

Idea, research, writing: C.L.E.

\section{COMPETING FINANCIAL INTERESTS}

The author declares no competing interest.

\section{METHODS}

Estimates of the incidence of intellectual disability shown in Table 1 are calculated from the relative incidence of mild $(85 \%)$, moderate $(10 \%)$, severe $(3.5 \%)$ and profound $(1.5 \%)$ intellectual disability (Boat and Wu, 2015, chap. 9), combined with an overall incidence of intellectual disability in the population of $0.9-3.7 \% \approx 2.3 \%$ (Boat and Wu, 2015, chap. 15). A similar estimates can be reached by assuming that IQ scores are roughly normally distributed. For a normally distributed variable, $2.3 \%$ of the probability mass is more than two standard deviations below the mean. Datasets from Clark et al. (2020) were downloaded from the online supporting material available at https://osf.io/ecdrt/. All code for plotting and analysis are available as a Jupyter Notebook (.ipybt notebook and .html render) as supplementary material.

\section{Bibliography}

APA, editor (1998). Diagnostic and Statistical Manual of Mental Disorders: DSM-IV. American Psychiatric Association, Washington, DC, 4. ed., 7. print edition.

APA, editor (2013). Diagnostic and Statistical Manual of Mental Disorders: DSM-5. American Psychiatric Association, Washington, D.C, 5th ed edition.

Bagby, E. T. (2011). Essays on Human Capital Development in Developing Countries. University of Illinois at Urbana-Champaign., USA.

Bakhiet, S. F. A., Abdelrasheed, N. S. G., Al-Khadher, M. M. A., Adan, M. H., Cheng, H., and Lynn, R. (2017). A Study of Sex Differences in Intelligence of Somali Refugees in Kenya. MANKIND QUARTERLY, page 7.

Becker, D. (2019). The National IQ dataset (Version 1.3.2). https://viewoniq.org/?page_id=9.

Becker, D. and Rindermann, H. (2016). The relationship between cross-national genetic distances and IQ-differences. Personality and Individual Differences, 98:300-310.

Belkhir, J. (1994). Race, Sex, Class \& "Intelligence" Scientific Racism, Sexism \& Classism. 1(2):53-83.

Boat, T. F. and Wu, J. T., editors (2015). Mental Disorders and Disabilities among Low-Income Children. National Academies Press, Washington, D.C.

Buckley, G. J., Murray-Kolb, L. E., Khatry, S. K., Leclerq, S. C., Wu, L., West, K. P., and Christian, P. (2013). Cognitive and motor skills in school-aged children following maternal vitamin A supplementation 
during pregnancy in rural Nepal: A follow-up of a placebo-controlled, randomised cohort. BMJ open, 3(5).

Christian, P., Murray-Kolb, L. E., Khatry, S. K., Katz, J., Schaefer, B. A., Cole, P. M., Leclerq, S. C., and Tielsch, J. M. (2010). Prenatal micronutrient supplementation and intellectual and motor function in early school-aged children in Nepal. JAMA, 304(24):2716-2723.

Clark, C. J., Winegard, B. M., Beardslee, J., Baumeister, R. F., and Shariff, A. F. (2020). Declines in Religiosity Predict Increases in Violent Crime-but Not Among Countries With Relatively High Average IQ: Psychological Science, 3(2):170-183.

Cotten, J. (1985). Evaluation Research on the PL 480 Title II School Feeding Program in Haiti. USAID/Haiti, Port-au-Prince. de Ronceray, H. and Petit-Frere, S. (1975). Project experimentale sur le bilinguisme Creole-Francais au niveau de l'enseignement primaire en Haiti. Bulletin d'Informations du CHISS, 4:2-25.

Dickins, T. E., Sear, R., and Wells, A. J. (2007). Mind the gap(s)... in theory, method and data: Re-examining Kanazawa (2006). British Journal of Health Psychology, 12(Pt 2):167-178.

Durbrow, E. H., Schaefer, B. A., and Jimerson, S. (2002). Diverging Academic Paths in Rural Caribbean Village Children: Predicting Secondary School Entrance from the St Vincent Child Study. School Psychology International, 23(2):155-168.

Gould, S. J. (1981). The Mismeasure of Man. Norton, New York, 1st ed edition.

Hampshire, A., Highfield, R. R., Parkin, B. L., and Owen, A. M. (2012). Fractionating Human Intelligence. Neuron, 76(6):1225-1237.

Jamison, D. T. and Moock, P. R. (1984). Farmer education and farm efficiency in Nepal: The role of schooling, extension services, and cognitive skills. World Development, 12(1):67-86.

Loehlin, J. C. (2007). Book review: Richard Lynn, Race Differences in Intelligence: An Evolutionary Analysis. Intelligence, 35(1):93-94.

Lynn, R. and Becker, D. (2019). The Intelligence of Nations. Ulster Institute for Social Research, London.

Lynn, R. and Meisenberg, G. (2010). National IQs calculated and validated for 108 nations. Intelligence, 38(4):353-360.

Lynn, R. and Vanhanen, T. (2002). IQ and the Wealth of Nations. Human Evolution, Behavior, and Intelligence. Praeger, Westport, Conn.

Lynn, R. and Vanhanen, T. (2012). INTELLIGENCE: A Unifying Construct for the Social Sciences. Ulster Institute for Social Research, London.

Maqsud, M. (1997). Effects of Metacognitive Skills and Nonverbal Ability on Academic Achievement of High School Pupils. Educational Psychology, 17(4):387-397.

Richardson, K. (2002). What IQ Tests Test. Theory \& Psychology, 12(3):283-314.

Richardson, K. (2004). IQ and the Wealth of Nations. Heredity, 92(4):359-360.

Van de Vijver, F. J. R. and Brouwers, S. A. (2009). Schooling and basic aspects of intelligence: A natural quasi-experiment in Malawi. Journal of Applied Developmental Psychology, 30(2):67-74.

Veii, K. (2003). Cognitive and Linguistic Predictors of Literacy in Namibian Herero-English Bilingual School Children. Department of Psychology of the School of Human Sciences of the University of Surrey in Guildford, United Kingdom.

Wicherts, J. M., Borsboom, D., and Dolan, C. V. (2010a). Why national IQs do not support evolutionary theories of intelligence. Personality and Individual Differences, 48(2):91-96.

Wicherts, J. M., Dolan, C. V., Carlson, J. S., and van der Maas, H. L. J. (2010b). Raven's test performance of sub-Saharan Africans: Average performance, psychometric properties, and the Flynn Effect. Learning and Individual Differences, 20(3):135-151.

Wicherts, J. M., Dolan, C. V., and van der Maas, H. L. J. (2010c). The dangers of unsystematic selection methods and the representativeness of 46 samples of African test-takers. Intelligence, 38(1):30-37.

Wicherts, J. M., Dolan, C. V., and van der Maas, H. L. J. (2010d). A systematic literature review of the average IQ of sub-Saharan Africans. Intelligence, 38(1):1-20. 